\title{
The dynamics of purposeful change: a model
}

\author{
$\underline{\text { Howard Silverman }}^{1}$ and $^{\text {Gregory M. Hill }}{ }^{2}$
}

ABSTRACT. In order to describe and depict the dynamics of purposeful change, we reexamine the concept of social-ecological systems (SES) and propose a linked but not integrated SES model. Adapting core resilience tools (stability landscape and panarchy), we construct a general model and then use a framework of key concepts (identity, logics, affiliations, affordances) to analyze the dynamics depicted therein. We illustrate this model's use in two cases: a retrospective analysis of food-systems work amidst contending social regimes and an interpretive reading of published narratives describing individual-to-ecological stability and change. We discuss this model's applicability in situations involving divergent perspectives, micro-meso-macro social dynamics, social regime identity, and the distinct dynamics of social and ecological systems. This examination illustrates the power and flexibility of these core resilience tools.

Key Words: bricolage; institutional logics; path dependence; reflexivity; social attractors; system archetypes

\section{INTRODUCTION}

Efforts to describe and depict the dynamics of purposeful change, from the individual level to the ecological, encounter numerous challenges. By definition, such efforts must bridge across or be fragmented by academic disciplines. Conceptual tools (e.g., models, methods, metaphors) developed in one context may not apply to another.

A strength of resilience scholarship is its shared set of tools for conducting interdisciplinary examinations. However, and as we will illustrate, the dynamical systems modeling developed by resilience scholars for the study of ecosystems does not directly translate to the social domain (Anderies and Norberg 2008, Byrne and Callaghan 2014). In order to explore these complexities, we use core resilience tools, the stability landscape and panarchy, to construct a model of individual-to-ecological dynamics. Both these tools reflect a systems approach (Folke 2006), and we likewise follow a systems approach in adapting these tools.

This model development leads us to reexamine the concept of social-ecological systems (SES) (Folke 2016). We describe the SES as a tool for conceptualizing interrelationships across social and ecological system domains. This statement is not intended to question the reality of intertwined social and ecological phenomena. Indeed, humans are embedded in and dependent upon the natural world. While emphasizing the reality of such phenomena, we concurrently emphasize the conceptual nature of tools, such as SES models, with which one might investigate and understand such phenomena (Becker 2012). With this dual emphasis, we underscore the potential for multiple SES approaches.

To distinguish and discuss how social-ecological interrelationships might be conceptualized, we draw a distinction between integrated and linked SES approaches. We describe an "integrated" or "unit-of-analysis" approach as typified by the combined representation of social and ecological dynamics in a single stability landscape (Sendzimir et al. 2007, Westley et al. 2011, Rockström 2014, Allen et al. 2016). In contrast, we describe "linked" or "linked-but-not-integrated" SES approaches as emphasizing social-ecological interactions while also "explicitly distinguishing" between the dynamics of social and ecological system domains (Manuel-Navarrete 2015).

This paper's outline is as follows. In a Theoretical Background section, we use two core resilience tools, the stability landscape and panarchy, to construct a linked-but-not-integrated SES model. In the Methods section, we describe our approach to developing and illustrating this model's use as an analytical tool. We develop this tool by analyzing its depiction of individual-toecological dynamics, and we illustrate its use in two case studies. Lastly, we discuss this model's practical applications and conclude by revisiting our initial propositions.

Questions about SES integration are not new. Holling (2001) and Westley et al. (2002) sought to distinguish ways in which human capabilities differ from those of other species. Walker et al. (2006) expressed cautions about "a common framework of system dynamics" before proposing its adoption. Since then, scholars have challenged integrated treatments of social and ecological dynamics (Hatt 2013, Brown 2016). What are the implications of integrating or linking depictions of social-ecological dynamics in a general model? This question animates our investigation.

Linked SES models can have significant practical applications. The focus of resilience scholarship on transformability (Folke et al. 2010, Smith and Stirling 2010, Pelling et al. 2012, Olsson et al. 2014) points to the value of granular resolution on social dynamics. We discuss this model's applicability in four types of situations, involving divergent perspectives, micro-meso-macro social dynamics, social regime identity, and the distinct dynamics of social and ecological systems.

\section{THEORETICAL BACKGROUND}

In this section, we use the stability landscape and panarchy to construct a model of individual-to-ecological dynamics. First, we examine the development of the stability landscape and the challenges of its use in the social domain. Then we examine how the concept of panarchy might be used to link individual-toecological dynamics. Because this model construction represents an examination and adaptation of core resilience tools, we label this section theoretical background. 


\section{Stability landscape}

The stability landscape is a tool for examining the dynamics of stability and change in terms of current and potential system regimes (Walker et al. 2004, Scheffer 2009). Explicit or implicit in the use of the stability landscape is the selection of a focal system (Resilience Alliance 2010, Walker et al. 2012). We begin by describing the distinction-making and perspective-taking involved in such a selection.

We describe three stages of distinction-making in selecting a focal system. In everyday experience, each of us is surrounded and subsumed by the flux of life, physical and mental, unconscious and conscious. Amidst this flux, we perceive situations, experience reactions, and make judgments (Bandura 1991, Ison 2010). Some situations might be interpreted as areas of concern or opportunity; that is, areas in which an activity or change might be desirable. People with a tendency toward systems thinking might then consider one or more systems as affecting or affected by this area of concern or opportunity, and then one or more of these as systems in need of attention: the focal systems. These three stages of focusing - on a particular situation, on a systemic view of this situation, and on particular focal systems - are each instances of distinction-making. These distinction-making acts are inherently normative and hence dependent on individual perspective (van Lieshout et al. 2011). We describe "perspective" as the set of situated experiences, interests, and values that one brings to the activity of perceiving and interpreting situations in the world. For example, one person might be concerned about the climate situation, while another focuses on daily needs. Or sharing concerns about climate, one might understand and express one's concerns in systems language, while another turns to the discourse of power relations. Or taking a systemic approach, one might focus attention on ecological function, while another focuses on global capitalism and a third on electricity generation.

Holling (1973) developed the foundations of resilience science by analyzing ecological focal systems with the then-emerging tools of complexity theory: dynamical systems modeling of feedbacks and attractors within state space (Folke 2006). To define state space, a set of quantitative variables is first chosen and used to specify potential states of the system. State space is then defined as the space of all values of the state variables. Within state space, the stability landscape is the subset of all points that represent actual possible states of the system, according to a set of mathematical constraints. Dynamic change can then be represented by the motion of a point (the current state of the system) on the stability landscape. The valleys on this metaphorical landscape are called "basins of attraction" or "regimes." Each basin or regime represents the collection of system states that falls within a zone of stability. Stated another way, each basin or regime represents the collection of potential states for which the ecosystem can absorb disturbances while maintaining existing feedbacks, functions, and identity (Scheffer 2009). Within state space, attractors are the stable or equilibrium states toward which other systems states tend to evolve over time. The collection of these nearby "attracted" states forms the regime specified by the attractor (Scheffer 2009). Only after many years of theoretical development and on-the-ground research did this type of systems modeling gain widespread acceptance in the ecology field (Folke 2006, 2016). It now informs resilience research on ecosystems around the world (Folke 2016).
The stability landscape model has also been used to represent an integrated understanding of social-ecological stability and change (Sendzimir et al. 2007, Westley et al. 2011, Rockström 2014, Allen et al. 2016). We understand the integrated approach to stability landscape construction as follows. The integrated landscape is a visual metaphor that represents the combined ecological and social (including material) conditions within which individuals and organizations operate (Westley et al. 2011, Allen et al. 2016). This integrated landscape may represent the combined use of ecological and social variables in an analysis of feedbacks (Sendzimir et al. 2007). It may also represent a relative analysis of contributions to resilience among identified ecological and social variables (Allen et al. 2016). On an integrated landscape, differing regimes represent differing "development trajectories" (Enfors 2013:53), each of which delivers a particular "bundle" of ecosystem services (Cumming and Peterson 2005:47). In other words, alternative regimes on an integrated landscape represent plausible social systems that deliver differing social and environmental outcomes. A well-documented challenge of using the integrated SES approach is that social activities may not "fit" the spatial extents of an ecological focal system (Folke et al. 2007), and Cumming et al. (2012) proposed strategies for "solving the problem of social-ecological scale mismatches."

In contrast to an integrated SES approach, we describe distinctions between ecological and social domains as follows. If one's focus is the abundance of fish, availability of freshwater, regulation of climate, or any other description of an ecosystem service, then we understand the selected system or systems as in the ecological domain, even though social actors and social processes may constitute the principal drivers of ecosystem change. If one's focus of attention shifts to these social actors and processes, we understand the selected system or systems to be in the social domain.

An example from fisheries systems can serve to illustrate these distinctions. If we specify the abundance of a particular fish species, over a particular spatial and temporal extent, then our focal system is in the ecological domain. In this case, the current state of the system would be described by specifying quantitative values. However, if we describe the provisioning of fish through harvest practices, regulatory policies, supply chain networks, and/ or the operation of port and processing facilities, then our focal system or systems are in the social domain. In this case, the dominant regime or regimes would be described in social terms, consisting of the current practices, policies, networks, and/or facilities through which fish are provisioned. Dominant social regimes are sometimes described as "business as usual" (Walker and Salt 2006:51), and alternatives are sometimes described as "niche regimes" (Westley et al. 2011). Even if a system is viewed in the social domain, social-ecological interactions may be essential to understanding its current or potential regime or regimes.

A challenge of using these resilience tools in social situations is that dynamical systems modeling does not directly translate to the social domain (Anderies and Norberg 2008, Byrne and Callaghan 2014). For example, while the attractor concept is well described for ecological systems, the concept of "social attractors" remains less clear. As Anderies and Norberg (2008:172) maintained, "A fundamental yet still undeveloped area 
in complexity theory is the notion of social attractors." This caution applies to use of the stability landscape in the social domain as well.

Two distinctions between research on ecological versus social systems can be illustrated by a comparison of stability landscape applications, mathematical and metaphorical. First, in the ecological domain, a point or ball on the landscape is typically used to represent the current state of the evolving system. The location of the point or ball is specified by the quantitative state variables (Walker et al. 2004). However, in the social domain, it may not be possible or appropriate to specify the state of the system so precisely, and the ball may be used merely to indicate the dominant or focal regime or regimes within the focal system (Westley et al. 2011). This distinction points to the value of a granular analysis of social regimes. Second, in mathematical terms, the stability landscape is used to represent all possible states of the system for the selected variables. However, and perhaps particularly in the social domain, it is not appropriate to claim anticipatory knowledge of all such possibilities. Instead, the stability landscape may be used to indicate the dominant regime or regimes and "adjacent possible" regime or regimes (Kauffman 2000:142, Westley et al. 2016). This distinction points to the value of granular resolution on interrelationships between the actors seeking to establish such adjacent regimes and the landscapes of social possibilities available to each. These two distinctions in applying the stability landscape model to the social domain will inform our analysis, as described in the Methods section.

\section{Panarchy}

The panarchy is a multilevel model for examining ways in which organization and structure emerge in complex systems (Holling 2001, Allen et al. 2014). In order to examine how the concept of panarchy might be used to link individual-to-ecological dynamics, we classify the panarchy as a type of scalar model and begin with a description of such models.

Following Gibson et al. (2000), Cash et al. (2006), and Vervoort et al. (2012), we adopt the terminology in which a "scale" is an ordered grouping of structures or processes, and a "level" is a unit of analysis on a scale. For example, one might recognize daily, seasonally, and annually levels on a temporal scale, or operational, tactical, and strategic levels on a planning scale. In these terms, a comparison of temporal and planning interrelationships would be cross-scale, and a comparison of operational and tactical interrelationships would be cross-level. Given this terminology, the panarchy can be understood as a particular type of scalar model.

In applying the panarchy model to an examination of purposeful change in social systems, we follow Friedland and Alford (1991), who described the three-level model of individual-organizationalsocial (micro-meso-macro) relations as "necessary to adequately understand society" (Friedland and Alford 1991:242). This social scale makes possible examinations of agency as both individual and collective (i.e., individual and organizational) and of the social structuring and social innovation processes that take place across levels. In these terms, we describe organizational-level systems as groups of individuals (e.g., businesses, NGOs, shadow networks, communities of practice) who come together, formally or informally, to express some aligned or shared purpose, and we describe social-level systems as including "society" as well as systems of a more broadly or narrowly defined political, economic, cultural, or other nature.

In the resilience literature, Friedland and Alford's (1991) social scale is represented in the models of Westley (2002). In a Panarchy book chapter and based on indepth interviews, Westley (2002) described the experiences of an adaptive manager, engaging in purposeful efforts to influence multiple natural resource management regimes, while experiencing evolving and diverging senses of his own agency or identity, with respect to each regime. Westley (2002) illustrated these interrelated dynamics in multiple models of the social scale, each consisting of four levels (individual-interorganizational-organizational-political), with each level depicted as an adaptive cycle of renewal and collapse. In effect, Westley's (2002) social scales are panarchies, though not identified as such (Holling 2001).

In order to develop a granular examination of social and socialecological dynamics, we adopt this social scale and extend it to include an ecological level (Fig. 1).

Fig. 1. A scalar model of purposeful change dynamics. Individual, organizational, social, and ecological levels of interaction are each depicted with a simplified two-basin landscape to represent the attractor-based dynamics of current and potential regimes, each characterized in terms of identity. Constraints and affordances occur in two directions: within each level and through the panarchy. In these terms, ecological regimes constrain and afford the viability of potential social regimes, which in turn constrain and afford the viability of potential organizational regimes, which in turn constrain and afford the viability of potential individual affiliations of activity and identity. Concurrently and from the bottom up, individuals shape and affiliate with organizational regimes, individual shaping of and affiliation with social regimes may or may not be mediated through organizational regimes, individuals and organizations each shape and affiliate with numerous social regimes, and even the proverbial individual who lives apart from all social regimes must seek, and therefore shape, regimes of ecological affordances.

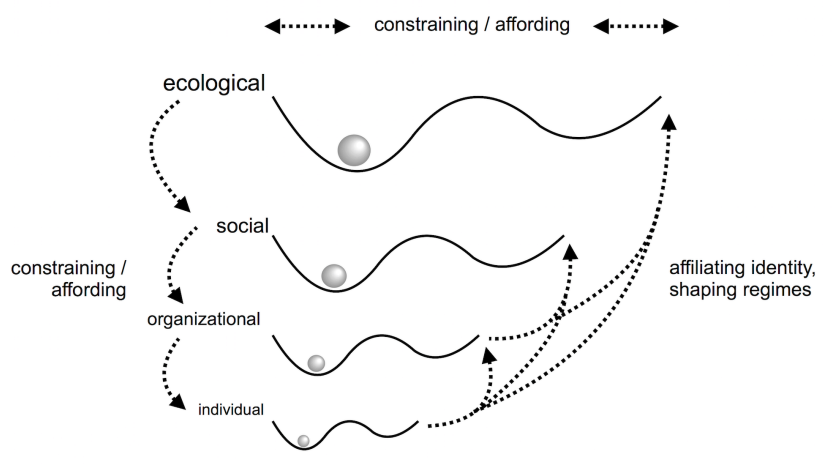

We label Fig. 1 "a scalar model of purposeful change dynamics," and we use these terms as follows. We use "dynamics" to mean change over time, and specifically, change that is influenced by systemic properties or phenomena (e.g., feedbacks, attractors). We use "purposeful" to mean the expression of agency or will (Ison 2010). We describe "models" as representations and 
Table 1. Framework of key concepts used in analyzing the dynamics of a scalar model that links the individual level with the ecological.

\begin{tabular}{|c|c|c|}
\hline Concept & Use of this concept & Rationale for selecting this conceptual approach \\
\hline Identity & $\begin{array}{l}\text { Analyzing the essential continuity of focal } \\
\text { regimes over time and space }\end{array}$ & $\begin{array}{l}\text { A flexible and coherent approach to analyzing stability and change } \\
\text { in and across systems that are variously individual, organizational, } \\
\text { social, or ecological in nature }\end{array}$ \\
\hline Institutional logics & $\begin{array}{l}\text { Analyzing the social factors underlying essential } \\
\text { relationships through which social regimes are } \\
\text { perceived, experienced, and understood }\end{array}$ & $\begin{array}{l}\text { A well-developed literature that (1) is compatible with a dynamical } \\
\text { systems approach, (2) provides a systematic, granular analysis of } \\
\text { social factors, and (3) describes a "transposition" strategy for } \\
\text { purposeful change }\end{array}$ \\
\hline Affiliations & $\begin{array}{l}\text { Analyzing the experiences and effects of regime } \\
\text { participation and/or identification }\end{array}$ & $\begin{array}{l}\text { An approach that (1) can be used to investigate and understand the } \\
\text { experiences of individuals and the effects on organizations of regime } \\
\text { attractors and feedbacks, (2) is inclusive of systems theorizing on } \\
\text { path dependence and social science theorizing on embeddedness, and } \\
\text { (3) is applicable across social and ecological domains }\end{array}$ \\
\hline Affordances & $\begin{array}{l}\text { Analyzing systemic opportunities: the set of } \\
\text { conditions that allow for activities that either } \\
\text { reinforce stability or engender adaptive or } \\
\text { transformative change both within and across } \\
\text { scalar levels }\end{array}$ & $\begin{array}{l}\text { An approach that (1) is particular to an individual or organization, } \\
\text { (2) is applicable to this individual's or organization's own identity } \\
\text { development, and (3) is applicable to this individual's or } \\
\text { organization's activities, across levels in this scalar model }\end{array}$ \\
\hline
\end{tabular}

abstractions that are used in investigating and understanding "how things work" (Rapoport 1985:256, as cited in Berkes and Folke 1998:15). In our usage, models are not necessarily mathematical, empirical, or predictive. Rather, they are "conceptual tools" that may aid in developing insights, identifying questions, guiding strategic practice, and so on (Fazey 2010).

Fig. 1 is both like and unlike the panarchy model. Like in the panarchy, Fig. 1 illustrates dynamical interrelationships both within and across levels. Unlike in the panarchy, we represent the dynamics within each level not in terms of an adaptive cycle but in terms of a stability landscape. We use this alternative approach because our emphasis, at each level, is on a stability-and-change view of dynamics, rather than on the adaptive cycle's stages.

The cross-level dynamics depicted in this model represent an interconnected top-down and bottom-up view. From the top down, ecological conditions and processes can constrain and/or enable stability and change at all social levels. From the bottom up, purposeful actors can initiate and scale up transformative innovations, influencing stability and change across the scale.

\section{METHODS}

Having now constructed the scaffolding of a four-level scalar model, in this section we describe our approach to developing and illustrating its use as an analytical tool.

In order to develop this model as an analytical tool, we use a framework of key concepts to analyze its representation of within-level and cross-level dynamics. These four concepts are identity, logics, affiliations, and affordances. Our selection of these concepts is informed by our comparative examination of stability landscape applications. This examination pointed to the value of more granular analyses of both social regimes and dynamic interrelationships between purposeful actors and social regimes.

We use these framework terms as follows. We use "identity" to mean the continuity of essential relationships, whether in individual, organizational, social, or ecological systems (Cumming and Collier 2005, Cumming et al. 2005). We turn to the literature on "institutional logics" (Thornton et al. 2012) to inform a granular examination of social regimes. We use "affiliation" to characterize the experiences and effects of regime participation and/or identification. And, we use "affordances" to characterize systemic opportunities: the set of conditions that allow for activities that either reinforce stability or engender adaptive or transformative change both within and across scalar levels. We summarize our use of these terms and rationale for the selection of each in Table 1.

This paper is interdisciplinary. We use the word "systems" broadly, drawing from scholarship self-described in terms that include cybersystemics (Ison 2010), complex systems (Page 2006), and networks (White 2008). We also draw from the works of scholars who may not be generally associated with these or other systems traditions but who nonetheless use systems concepts, whether in cognitive psychology (Bandura 1991) or historical sociology (Mahoney 2000). Third, we draw from writings that, though not specifying systems concepts, we propose as consistent with our dynamical systems interpretation, such as Thornton et al. (2012) on institutional logics.

After analyzing these individual-to-ecological dynamics, we illustrate this model's use in two case studies. We use this model to retrospectively analyze one case in which the first author on this paper participated and to inform an interpretive reading of a second case consisting of two published narratives. Our selection of these cases is purposeful, per Patton's (2015:46) description of "purposeful sampling" as a strategy in which "[c]ases for study... are selected because they are 'information rich' and illuminative, that is, they offer useful manifestations of the phenomenon of interest."

As Westley et al. (2016) described, a retrospective or historical analysis is well suited to formulating understandings of complex situations, and the understandings so developed may then inform subsequent, perhaps empirical, research. This approach might be narrative-based and/or retroductive, "in which events are explained by postulating (and identifying) mechanisms which are capable of producing them" (Sayer 1992:107, as cited in Byrne and Callaghan 2014:174). In this way, the cases described herein 
helped us formulate our analysis of this model, and in applying this model to these cases, we describe how this model has aided or might aid in developing insights, identifying questions, and guiding strategic practice. Then, in the Discussion section, we examine potential applications of this model in future research.

\section{ANALYZING A MODEL OF INDIVIDUAL-TO- ECOLOGICAL DYNAMICS}

We analyze the dynamics represented in this model (Fig. 1) in four subsections, based on the four concepts in Table 1 (identity, logics, affiliations, affordances).

\section{Perspectives on social regime identity}

In this subsection, we discuss social regime identity. Later, we will link the concepts of individual and social regime identities.

Resilience theorists have used the concept of "identity" to describe and examine "the essential nature of a system" (Walker and Salt 2012:215), and we follow this "identity approach" to describing social regimes. Drawing on methods from ecological systems, Cumming and Collier (2005) and Cumming et al. (2005) characterized regime identity through the specification of variables, essential relationships among those variables, relevant spatial extents, and so on. In the social domain, we likewise consider fundamental factors and their relationships in defining identity, while explicitly taking into account the differing perspectives of social actors.

To illustrate, consider systems theorist Vickers's (1980:82) brief reflection on "identity and continuity":

\begin{abstract}
My home town remains for me its old self though it has vastly grown and changed, and I have long since ceased to live there. But if some other old inhabitant said that for him it was no longer the same place, I should not assume that he or I must be wrong. I should only assume that some relationships now lacking were for him essential to the system called by that city's name, whilst for me they were not.
\end{abstract}

The focal system in Vickers's reflection is a particular place, his home city. Each inhabitant perceives a set of essential relationships: an identity. This identity may differ among individuals according to perspective, so that over time one might experience essential continuity while another experiences fundamental change.

In order to model the social regimes experienced by these two individuals, one would need to elicit from each his/her understanding of the city's essential relationships and their underlying social factors. Based on Vickers's narrative, we anticipate that these would differ greatly. If these social factors are then considered as state variables specifying state space, one would see that these two people are, in effect, seeing different landscapes. On Vickers's landscape, the identity of the city has stayed the same; it has undergone an adaptive change, but remains in the same regime. However, on the landscape of the "other old inhabitant," the dominant regime has undergone a shift to a new regime, characterized by a different identity.

\section{Social regime identity and institutional logics}

In this subsection, we use institutional logics to characterize the social factors underlying the essential relationships of regime identity. The literature on institutional logics is a good fit for our model because it provides a granular analysis of social factors and proposes a "transposition" strategy for purposeful change.

With the institutional logics approach, organizational theorists Thornton and colleagues systematically developed Friedland and Alford's (1991:232) "interinstitutional system" (micro-mesomacro, individual-organizational-social) "as a recursive theory of society that incorporates individuals and organizations" (Thornton et al. 2012:50). They defined an institutional logic as "the socially constructed, historical patterns of cultural symbols and material practices, including assumptions, values, and beliefs, by which individuals and organizations provide meaning to their daily activity, organize time and space, and reproduce their lives and experiences" (Thornton et al. 2012:2). In these terms, each social regime operates according to a particular institutional logic. Concurrently and amidst the multiplicity of institutional logics, there are "ideal types," based on traditional "institutional orders" - the family, the community, the market, the state, and so oneach of which "presents a unique view of rationality" (Thornton et al. 2012:10,73). Given the entanglements of contemporary social life, social regimes are, in effect, "hybrids" of such ideal types (Pache and Santos 2013:972).

Using institutional logics to describe social regime identities, we can add additional detail to the transformation strategies described, for example, by Westley et al. (2011) and Olsson et al. (2014). For actors engaging in purposeful change, the hybrid nature of social regimes suggests methods for envisioning and developing alternatives based a recombination or "transposition" (Thornton et al. 2012:62) of logics. Thornton and colleagues described the transposition of logics as a "bricolage" in which a regime proponent "draws upon logics as a kind of cultural toolkit" so as to exploit "institutional contradictions" (Thornton et al. 2012:77,144). In this way, one might seek to adopt metaphors, values, or practices from either contending regimes or ideal types so as to recombine them in strengthening the resilience of one's preferred regime. We examine such efforts and their strategic potential in the contending-regimes case.

\section{The dynamics of regime affiliation}

In this subsection, we use the term affiliation to characterize interrelationships between individual identity and social regime identity. In other words, we use the term affiliation to describe the experiences of individuals (and effects on organizations) of regime participation and/or identification. The phenomenon of affiliation has been characterized in various ways, including as path dependence (Page 2006), behavioral lock-in (Barnes et al. 2004), and the paradox of embedded agency (Battilana et al. 2009).

Our framework concepts of identity, logics, and affiliation can now be conceptually linked as follows. The institutional logic (i.e., the constellation of metaphors, values, practices, and so on) through which one experiences the identity of the regime "attracts" (or "repels") one's affiliation with the regime, and in relation with a multiplicity of such regime affiliations, one's own identity develops. Moreover, given each person's multiplicity of regime affiliations, individual identity can be described plurally (Stryker and Burke 2000, White 2008). As an illustration, recall Westley's (2002) adaptive manager, seeking to influence multiple natural resource management regimes, and experiencing evolving and diverging senses of his own agency or identity, with respect to each. 
Based on this description of affiliation, multiple interconnected lines of analysis may be pursued. We focus here on four that will be illustrated in the case studies: the individual experience of regime affiliations, the exercise of power, the perspectivedependence of feedbacks, and the awareness of one's regime affiliations.

With regard to individual experience, the strength of one's affiliations can vary greatly. One's affiliation might be weakly based on habits or routines or it might include a stronger sense of commitment (Stryker and Burke 2000). Stated another way, one's affiliation might be based merely on utility or functionality, or it might be reinforced by a stronger sense of regime legitimacy, and/ or it might be reinforced by the sense of power that one derives from the regime's persistence (Mahoney 2000). Moreover, one might be influenced by feelings of security, anxiety, and so on about affiliating with or seeking to switch affiliations from a particular regime (Masten and Obradović 2008, Swim et al. 2009).

Mahoney (2000) and Pierson (2015) analyzed social and political power in terms of path dependence, and we follow this approach in proposing that the exercise of power can be analyzed as the capacity to act so as to strengthen regime affiliations. In these terms, proponents of a dominant regime can seek to strengthen regime resilience by strengthening the affiliations of individuals and organizations, through the experiences of utility, function, legitimacy, security, and so on. On the other hand, proponents of an alternative regime (i.e., "institutional entrepreneurs") (Moore and Westley 2011) face the challenge of establishing and nurturing nascent affiliations.

We describe the perspective-dependent role of affiliation in feedback analysis as follows. In ecological systems, balancing (i.e., negative or attenuating) feedbacks are typically described as "stabilizing," while reinforcing (i.e., positive or amplifying) feedbacks "tend to destabilize the system" (Chapin et al. 2009:10). This general understanding of ecological feedbacks is itself not a firm rule, as for example in the case of fire, which can function as a reinforcing feedback that stabilizes a forest regime (Bennett et al. 2005). In social and social-ecological systems, the experiences and effects of regime affiliation become important to feedback analysis. Reinforcing feedbacks stabilize the social level of a linked social-ecological system to the extent that they, in Page's (2006:89) terms, strengthen "behavioral routines, social connections, or cognitive structures" among affiliating participants. Attention to the perspective-dependence of feedbacks can inform examinations of and efforts to reconcile "different mental models" (Walker et al. 2012) of focal systems or regimes, as we will discuss.

To be aware of one's affiliations is to be like the proverbial fish, surprisingly aware of its watery surroundings. We describe an awareness of one's affiliations as a reflexive awareness: the physical-mental capacity to identify and reflect on one's current regime affiliations. For purposeful actors, a reflexive awareness of one's affiliations may be a precursor to seeking opportunities to weaken existing affiliations and strengthen alternatives.

\section{The dynamics of affordance}

In this subsection, we describe systemic opportunities in terms of affordances. The affordance concept is a good fit for our model because it allows for specificity in analyzing purposeful change both within and across levels of a linked social-ecological scale.
Environmental psychologist Gibson (1979:127) devised the word "affordance" to describe "something that refers to both the environment and the animal in a way that no existing term does." Chemero (2009) and Raymond et al. (2017) defined affordances as dynamic relations between the features of a situational environment and an individual organism's embodied abilities to perceive and act in such an environment. Thus, a tree presents an affordance for the squirrel but not for the dog chasing the squirrel.

In social terms, affordances point to opportunities availed by existing regimes, as well as by "adjacent possible" regimes, the "boundaries (of which) grow as you explore them" (Westley et al. 2016). Furthermore, affordances are specific to the individuals and organizations that seek to identify, create, and/or expand them. An affordance for you might not be so for me, and an affordance available to you tomorrow might not yet be available today.

Based on this specificity, the concept of affordances can be used to characterize potential for change in both directions of our model: within a level and across levels of the scale. Horizontally and within a level (individual, organizational, social, ecological), the stability landscape represents the set of afforded (i.e., "adjacent") alternatives to dominant or current regimes (Kauffman and Gare 2015). Vertically and across levels, a scalar model of landscapes can be used to represent various affordances for social agency, individual and collective, with regard to existing or potential organizational, social, and ecological regimes (Gibson 1979, Archer 2003). Like systems theorist Kauffman and colleagues (Felin et al. 2014), we use the term affordances to indicate what are sometimes called enablements or enabling constraints. Like Chemero (2009) and Raymond et al. (2017), we characterize affordances as embodied, dynamic, relational, and situational, and extending this characterization, we further specify affordances in terms of a two-directional social-ecological scale, each level of which represents current and potential regimes. In practical and experiential terms, this two-directional consideration of affordances clarifies that as I, an individual, seek transformative social opportunities, my own affiliations, and therefore identity, will necessarily be affected as well.

\section{ILLUSTRATIVE CASES}

We illustrate use of this model in two examinations of practitioners' experiences.

The first is a retrospective analysis of strategic food-systems work performed by Ecotrust with the Roots of Change Council and Roots of Change Fund (Ecotrust 2005a, Silverman et al. 2005). We selected this case study for its multifaceted illustration of perspectives on focal systems, contending regime affiliations, and efforts to build resilience or promote transformation through the transposition of logics. This case also illustrates the adaptation of a model (i.e., the limits-to-growth archetype [Senge 1990]) from one context for use in another (i.e., from an organizational-social context to a social-ecological one). The principal investigator on this project was Eileen Brady, and the first author on this paper participated in this work.

The second case consists of brief interpretive readings of two published narratives of people whose work we have admired: the initiatives of John Fullerton, as self-described in Fullerton (2015) and published by Capital Institute, and the initiatives of Karl 
Kupers and Fred Fleming, as described in a case study published by The National Initiative on Agriculture of the Middle and The Center for Integrated Agricultural Systems, University of Wisconsin-Madison (Lev and Stevenson 2013). We selected these narratives for the ways in which they illustrate efforts to develop affordances for change across the levels of a linked socialecological scale. The first author on this paper interviewed Karl Kupers for an Ecotrust publication in 2005 (Ecotrust 2005b).

\section{Retrospective analysis: contending social regimes}

In 2003, the Roots of Change Fund, a coalition of United States and California public and private grantmakers, motivated by environmental, social, and economic problems with the dominant food system and dissatisfied with the pace of change, issued a request for proposals (Ecotrust 2005a). They sought consultants to work with the Roots of Change Council and Roots of Change Fund on (1) envisioning a sustainable food system for California, (2) outlining possible implementation strategies for realizing this vision, and (3) identifying indicators for measuring progress (Ecotrust 2005a). Ecotrust, a Portland, Oregon-based NGO, was awarded a part of this consulting project.

We focus here on one component of this project, its food-system diagrams, and specifically one set of these diagrams, which we have reviewed and redrawn (Fig. 2). In these diagrams, Silverman et al. (2005) modified and adapted the model called "limits to growth" (Senge 1990:95) or "limits to success" (Kim and Anderson 1998:43). In an organizational management book, Senge (1990:94) characterized the limits-to-growth model as one of the "archetypes" or "patterns of structure" that "recur again and again." According to Senge (1990:95), limits-to-growth patterns occur when "[a] reinforcing (amplifying) process is set in motion to produce a desired result. It creates a spiral of success but also creates inadvertent secondary effects (manifested in a balancing process) which eventually slow down the success" (Fig. 2a). Silverman et al. (2005) used this limits-to-growth pattern to depict contending social-economic regimes: the "U.S. conventional food and agriculture industry" and the "U.S. modern sustainable food and agriculture industry" (Fig. 2b and 2c).

Fig. 2b depicts the growth and attenuation of the "conventional" regime. Silverman et al. (2005) cited agricultural economists Cochrane (1993) and Gardner (2002), along with the project's research into stakeholder values (Ecotrust 2005a), in characterizing the growth of the "U.S. conventional food and agriculture industry" as based on an increasing specialization of production and a concentration of land ownership and markets, systematically supported through policy, finance, research, and media, to the affirmation of "industrial economy" values (i.e., logics), such as price, convenience, and efficiency (Fig. 2b, left). To describe the attenuation of this growth, Silverman et al. (2005) depicted five balancing feedbacks (Fig. 2b, right). One, ecological rather than social, fits Senge's (1990) description of inadvertent secondary effects: the increased demand relative to availability of ecosystem services. The other four are better characterized as purposeful responses initiated by contending social actors: public outcry over negative social and ecological impacts, regulation and litigation, the competitive development of the "U.S. modern sustainable food and agriculture industry" as an alternative regime, and an increase in global competition in producing food for U.S. consumption.
Fig. 2c depicts the growth and attenuation of the "sustainable" regime. Silverman et al. (2005) characterized the growth of the "U.S. modern sustainable food and agriculture industry" as supporting and being supported by the reinforcement of "sustainability values" (i.e., logics), such as interconnectedness, diversity, regeneration, and health (Fig. 2c, left). They depicted the attenuation of this growth with two balancing feedbacks: the challenges of competing with the "conventional" regime and the challenges of maintaining, among supporters, a commitment to growth (Fig. 2c, right). The project's theory of change was that in addition to efforts to weaken the resilience of the dominant regime (i.e., through "public outcry" and "regulation and litigation"), greater attention be given to strategic, "opportunities-based" efforts to "build broad alliances," so as to grow the alternative, "sustainable" regime into "a new mainstream" (Ecotrust 2005a:3-7).

These diagrams illustrate a transposition strategy (Thornton et al. 2012). In these terms, Ecotrust (2005a) and Silverman et al. (2005) described proponents of contending "conventional" and "sustainable" regimes as each seeking to strengthen the affiliations of participants through the recombination of attractors. Silverman et al. (2005) depicted these efforts with a double dotted line at the top in Fig. $2 b$ and $2 c$, a feature added to the original archetype. Silverman et al. (2005) portrayed proponents of the "conventional" regime as adopting (but not internalizing) the value of personal health from advocates of the "sustainable" regime (e.g., rebranding their products with the values of the alternative regime), and Ecotrust (2005a:13-17) urged proponents of the "sustainable" regime to further develop their niche alternative by researching, affirming, and adopting "bridge values" such as profitability, innovation, and ownership from advocates of the "conventional" regime. That is, Ecotrust (2005a:2) encouraged "sustainable" industry proponents to strategically embrace a commitment to social-economic growth as part of a "theory of change for moving the sustainable food system from niche to mainstream."

To what extent the resilience of the "conventional" regime (Fig. $2 \mathrm{~b}$, left) might, for participants, represent a desired result is a complex question, given the nature of affiliations. Individual experiences of regime affiliations can vary greatly. Using Mahoney's (2000) terms, for example, affiliation with the "conventional" food regime might be strengthened through perceptions of cost and convenience (utility), the assumption that such a regime might better feed the world (function), the sense that such a regime represents a fair, appropriate, or meaningful way for a food system to operate (legitimacy), and/or the advantages one derives from the regime's persistence (power). Moreover, adapting Battilana et al.'s (2009) terms, the paradox of embedded affiliation is that, given the historical strength of dominant regimes, even those who are attracted to the logics of alternatives may find themselves unwillingly or unwittingly participating in dominant ones. We each need to eat but, at the same time, may experience emotional conflict due to competing food-regime affiliations.

Regime proponents can be described as holding distinct perspectives on the focal systems and regimes represented in Fig. $2 \mathrm{~b}$ and $2 \mathrm{c}$. For proponents of the "conventional" industry, the reinforcing feedback in Fig. 2 b represents commitments to socialeconomic growth and to strengthening the affiliations of 
Fig. 2. Contending dynamics, reinforcing and attenuating. Fig. 2a shows the original "limits to growth" or "limits to success" archetype, redrawn from Senge (1990:97) and Kim and Anderson (1998:43). Ecotrust (2005a) and Silverman et al. (2005) used this archetype in applied food-systems work, with Fig. $2 \mathrm{~b}$ showing the reinforcement and attenuation of the "conventional" food-system regime, and Fig. 2c showing the reinforcement and attenuation of the "sustainable" food-system regime. Both Fig. $2 \mathrm{~b}$ and $2 \mathrm{c}$ include a double dotted line at the top, a feature added by Silverman et al. (2005) to the original archetype to indicate efforts by regime proponents to adopt and integrate values from the contending regime. In effect, these regime proponents sought to strengthen affiliations through recombinations of attractors; i.e., transpositions of logics (Thornton et al. 2012). Fig. $2 b$ and $2 c$ were reviewed and redrawn for clarity and fidelity to the pattern of feedbacks in the original archetype; they are reprinted here with permission from Roots of Change (http://www.rootsofchange.org/).

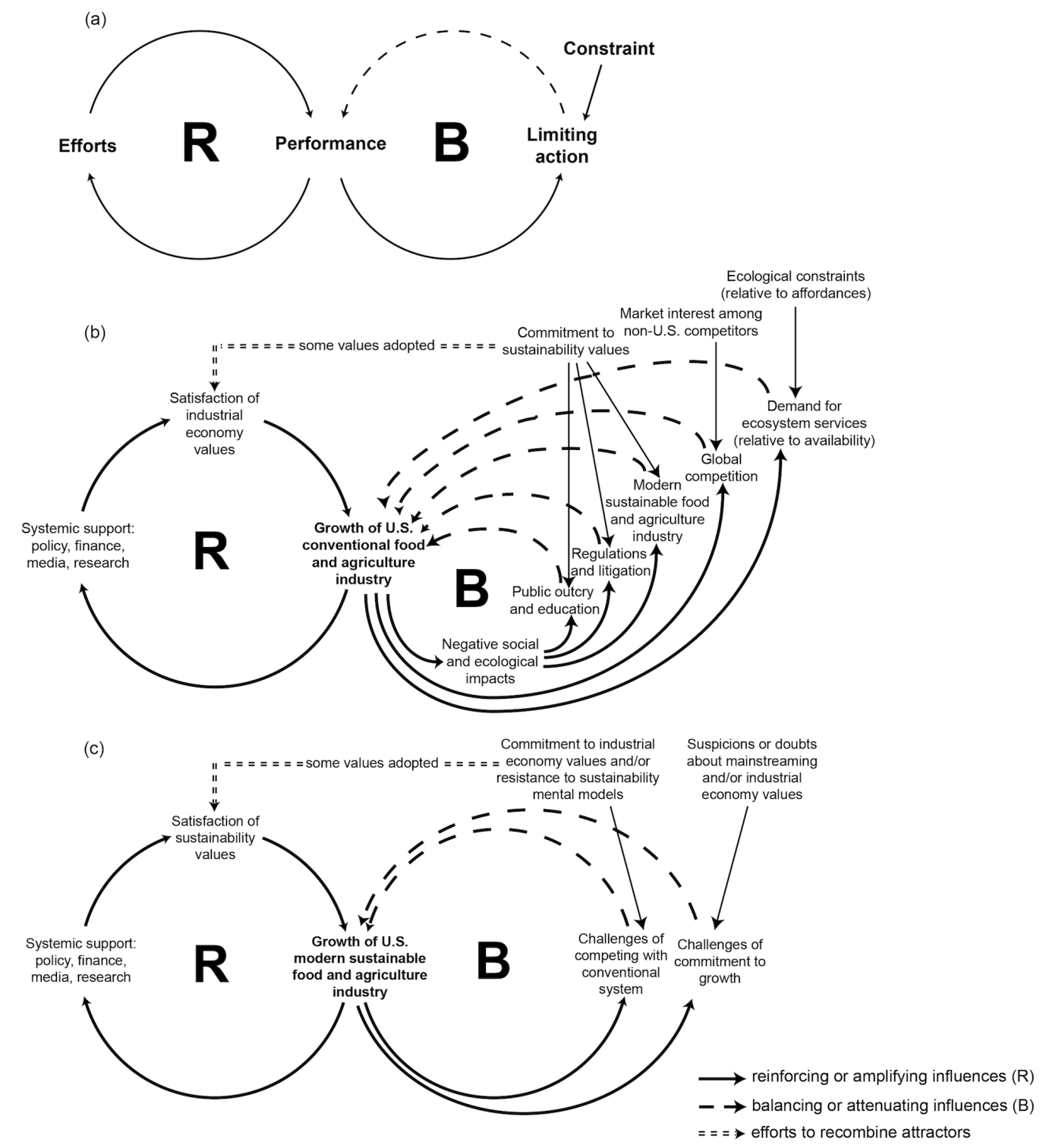

individuals and organizations, processes that, in effect, stabilize the "conventional" regime (Fig. 2b, left). Meanwhile, proponents of the "sustainable" industry focus attention on the "negative social and ecological impacts" of the "conventional" regime and respond in opposition, seeking to attenuate its further development (Fig. 2b, right). Viewing the focal system in the ecological domain, these "sustainable" industry proponents may see ecological systems as increasingly threatened by "conventional" practices, and in effect, see the system occupying a weakened regime. From this standpoint, the reinforcing 
feedback (Fig. 2b, left) would be seen as destabilizing and driving the state of the system toward a critical transition to an alternative regime with transformed ecological feedbacks, function, and identity. Turning to Fig. $2 \mathrm{c}$ and viewing the system in the social domain, the reinforcing loop represents, for proponents of the "sustainable" industry, commitments to social-economic growth and to strengthening the affiliations of participating actors, processes that, in effect, stabilize the "sustainable" regime (Fig. 2c, left). Significantly, these proponents may understand the same reinforcing loop as stabilizing the ecological regime as well, due to their view that the growth of their industry helps protect existing ecosystem feedbacks, functions, and identity. Thus, while this "sustainable" regime is vulnerable to attenuating feedbacks (Fig. 2c, right), Silverman et al. (2005) did not depict the attenuating feedback of increased demand relative to availability of ecosystem services (present in Fig. 2b but missing in Fig. 2c, on the far right).

In sum, we used this model, particularly the logics and affiliation concepts, to describe social regimes and analyze purposeful efforts for transformative change in terms of contending reinforcements and attenuations. We distinguished social and ecological dynamics in a linked social-ecological context, adding granular detail using the micro-meso-macro social scale. This added detail has allowed both an analysis of conflicting mental models in terms of differing perspectives and an illustration of novel strategies for transformation. We revisit these topics in the Discussion section.

\section{Interpretive readings: four levels of stability and change}

In published narratives, John Fullerton and Karl Kupers each expressed concerns about individual affiliations with particular social regimes. Mr. Fullerton, after a career at JPMorgan, became "disillusioned" with the culture of Wall Street and convinced that "the modern scheme of economics and finance" was the "root cause" of "the shocking prospect that we are destroying the planet's ability to support life as we know it" (Fullerton 2015:2). Mr. Kupers, after farming wheat conventionally for 10 years in Washington state, sought to "develop a farming business that is economically sustainable without depending on federal commodity subsidies" and their "support [for] monocultures which are the bases for most of our environmental problems" (Lev and Stevenson 2013:2). In ecosystem service terminology (which we adopt as common parlance), Mr. Fullerton's environmental concerns were described as "most notably" about climate regulation (Fullerton 2015:18), and Mr. Kupers's environmental concerns were described as about soil formation (Lev and Stevenson 2013:2).

Each then worked to develop affordances for change. In terms of the model described herein, each worked to develop the personal resilience for a shift in affiliations. Mr. Fullerton described years of searching and study "to find a credible alternative framework for economics and finance" (Fullerton 2015:2-3). Mr. Kupers and colleagues experimented with new crops, rotations, and directseed ("no-till") techniques (Lev and Stevenson 2013:2), in effect investigating ecological feedbacks so as to better understand ecological affordances.

Both Messrs. Fullerton and Kupers created organizations to act as proponents for alternative social regimes. Mr. Fullerton founded the nonprofit Capital Institute (Fullerton 2015:5). Mr. Kupers partnered with Mr. Fleming to establish two organizations, the Columbia Plateau Producers network of farmers and the Shepherd's Grain wheat flour marketing business (Lev and Stevenson 2013:2).

Through these organizations, Mr. Fullerton and Messrs. Kupers and Fleming each worked to develop the logics of an alternative social regime. For Mr. Fullerton, the focal system of attention might be described as dominated by a capitalism-as-usual regime, against which he offered an alternative vision of "regenerative capitalism," distinguished from the dominant regime by a set of key principles (Fullerton 2015:39-81). For Messrs. Kupers and Fleming, the systems of attention might be described as the ones through which wheat flour was produced and provisioned across the region, and in relation to which the 550,000 bushels of wheat marketed by Shepherd's Grain in 2011 represented an alternative niche (Lev and Stevenson 2013:15). Distinguishing characteristics of this niche regime were described as including the traceability of Shepherd's Grain flour and the practices whereby Shepherd's Grain and its customers agreed to sell and buy flour according to "cost of production plus a reasonable rate of return," rather than commodity market prices (Lev and Stevenson 2013:3-14).

In our interpretive readings and in terms of our four-level scale, Messrs. Fullerton, Kupers, and Fleming each engaged in purposeful change, individually and organizationally, so as to identify and develop perceived and afforded alternatives to social regimes that each considered problematic (capitalism-as-usual for Mr. Fullerton, wheat-production-and-provision-as-usual for Messrs. Kupers and Fleming), in order to maintain the resilience of desirable ecological regimes (regulating climate stability for Mr. Fullerton, provisioning soil fertility for Messrs. Kupers and Fleming) that each perceived as being destabilized by the dominant social regime.

With respect to these interpretive readings, several aspects of our model allow for granular investigation. For example, having a definition of social regime identity, analogous to the definition in the ecological domain, allows an investigation of in what respects the social innovations described in these narratives might be socially transformative and how such a social transformation might be linked to relevant ecological regimes and their ecosystem services. Moreover, if differing perspectives exist, concerning these social identities and innovations (i.e., the logics of the capitalism-as-usual regime and its envisioned alternative or the wheat-production-and-provision-as-usual regime and its niche alternative), this type of investigation might inform facilitation of a dialogue to develop shared strategy or strategic alignments.

\section{DISCUSSION}

Here, we discuss practical applications; i.e., use of this linked SES model to develop insights, identify questions, and guide strategic practice in situations involving divergent perspectives, micromeso-macro social dynamics, social regime identity, and the distinct dynamics of social and ecological systems.

"Setting soft boundaries-defining the focal system" was described as the first step in a resilience assessment (Resilience Alliance 2010:10). However, as Walker et al. (2012) described, people may come to such situations with "different mental models" about what constitutes the system. Elaborating on Resilience Alliance (2010) and Walker et al. (2012), we specified three stages of distinction-making in the selection of a focal 
system and emphasized interrelated ways in which differing perspectives arise: through the selection of focal systems and thus of potential regimes and through affiliations with regimes. As illustrated in Vickers's narrative, even when there is agreement on the focal system, divergent perspectives on regime identity may lead to starkly different interpretations. In this example, it was not merely that two people saw, or valued, a shared landscape differently. Rather, they experienced different landscapes entirely. In terms of this model, Vickers and his compatriot differently experienced the reinforcements of affiliation with an urban identity, past or present. A consideration of such affiliations may be informative, for example, when scholars or practitioners seek to engage and enable stakeholder alignment in contested situations, such as, in this case, urban development.

The micro-meso-macro social scale makes visible individual and organizational stability and change and their interrelationships with social regime stability and change. A consideration of such dynamics might inform several types of situations. Explicitly incorporating individual dynamics into the scope of one's examination enables an investigation of questions such as how social actors develop leadership capacities or why "triggering events" (Moore et al. 2014) influence some people but not others. Explicitly incorporating organizational dynamics enables an investigation of challenges such as establishing or maintaining organizational resilience, as distinct from yet interrelated with organizational efforts to influence the social-level systems that are the focus of collective attention.

In order to develop a granular conceptualization of social regime stability and change, we proposed an institutional logic as a descriptor of regime identity and hence an attractor. To summarize this analysis, picture Fig. $2 \mathrm{~b}$ and $2 \mathrm{c}$ mapped onto the two-basin stability landscape model (i.e., the social level in Fig. 1). In this mapping, Fig. $2 b$ describes the reinforcement and attenuation of the dominant social regime, and Fig. 2c describes the reinforcement and attenuation of the alternative niche social regime. In complement to the stability landscape, these diagrams illustrate, in general terms, the affiliations of individuals and organizations with contending reinforcing and attenuating processes, the processes through which the development of an alternative regime might attenuate the dominant one while also being vulnerable to attenuation, and the ways in which proponents of contending regimes might seek to transpose logics and recombine attractors so as to attract, affirm, and mobilize participants. This mapping points to opportunities for further research on ways in which the literatures on institutional logics and on a resilience-based theory of social attractors might inform each other. It also points to ways in which an institutional logicbased understanding of regime identity might inform strategies for purposeful change.

Distinct social and ecological dynamics are encountered in several types of situations. One situation is based on a "misfit" (Folke et al. 2007) between social and ecological change processes, such as when institutional structures exist at spatial extents that do not match relevant ecosystems. Another situation is when desires for ecosystem resilience are understood to require social transformation, as illustrated in the interpretive-readings case. A third or related situation arises when investigating feedbacks. As illustrated in the contending-regimes case, the reinforcing feedbacks that contribute to stabilizing a social regime may also contribute to destabilizing an ecological regime. In each of these situations, the linked-but-not-integrated SES model described herein may be useful for its distinctions between social and ecological dynamics.

\section{CONCLUSION}

We based our model construction on a close examination of the stability landscape and panarchy, following Westley (2002) in using resilience tools to conceptualize micro-meso-macro levels in social change processes, and adapting these tools to link individual-to-ecological dynamics in a general model. This examination illustrates the power and flexibility of these core resilience tools. While the dynamical systems modeling developed by resilience scholars for the study of ecosystems does not directly translate to the social domain, the dynamics-based tools of resilience scholarship can be used to construct the scaffolding of an individual-to-ecological model. Given our reliance on these tools, this model development represents a specifically resiliencebased approach to investigating efforts at purposeful change.

In order to analyze the dynamics of linked social and ecological systems represented in this model, we selected a framework of key concepts: identity, logics, affiliations, and affordances. We defined the identity of a social regime in terms of institutional logics, power as the capacity to act so as to strengthen regime affiliations, and reflexivity as the physical-mental capacity to identify and reflect on one's current regime affiliations. We described affordances for transformative change as relative both to the actors engaging in such efforts, individually and/or collectively, and to their current and potential regime affiliations, along the levels of a linked social-ecological scale. Each of these definitions and descriptions is based on core resilience concepts, such as regime and panarchy. A linked-but-not-integrated SES model, based on resilience concepts, may strengthen the ability of resilience scholars to take into account the roles of agency, power, and perspective, as they investigate and engage in efforts at purposeful change.

In the Discussion section, we proposed contexts for application of this model, but a broader view of these contexts was presented in a 2017 paper by Olsson, Moore, Westley, and McCarthy (Olsson et al. 2017). These authors outlined three strategic imperatives for social innovation theory and practice, given the challenges of the Anthropocene. In the first of these, they argued that "[e]conomic and social elements must be understood to be nested within ecosystems." We likewise depicted nested social-ecological relationships, embedding a social scale within a larger socialecological scale, with ecosystems at the top (Fig. 1). This type of model affirms the principle that "one cannot have a social innovation without an ecological impact, nor an ecologically based innovation without considering the social impact" (Olsson et al. 2017). In the second imperative, these authors argued for the importance of "confronting path-dependence" so that social innovations "will not reinforce the anthropogenic changes that led to the Anthropocene." By using institutional logics to define social regimes and by developing the concept of regime affiliation, we integrated the concepts of path dependence, behavioral lockin, and embedded agency into a resilience-based model. The authors then recommended that social innovators confront pathdependence through a bricolage method: "the recombination of 
pre-existing and new ideas, concepts or technologies." By tying the institutional logics strategy of "transposition" into our description of social regimes, we integrated a logics-based version of bricolage into a resilience-based model. The authors' third imperative concerned the multidimensional challenges of scale, whether social, temporal, or biophysical. They asked how an individual social innovator "can 'see' the social-ecological linkages across scales in which they may be directly working" and how research might help reveal these linkages. By representing individual actors in a general social-ecological model and by using core resilience concepts to describe the experiences and activities of individuals within linked social-ecological systems, we hope to have developed some conceptual tools for seeing and therefore engaging with these social-ecological relationships.

\section{Responses to this article can be read online at:} http://www.ecologyandsociety.org/issues/responses. $\mathrm{php} / 10243$

\section{Acknowledgments:}

We appreciate the ongoing work of Ecotrust, Roots of Change, Capital Institute, and Shepherd's Grain. We thank the anonymous reviewers of this article for their helpful comments. Peter and Trudy Johnson-Lenz also provided comments and conversations on an early version of this manuscript.

\section{LITERATURE CITED}

Allen, C. R., D. G. Angeler, A. S. Garmestani, L. H. Gunderson, and C. S. Holling. 2014. Panarchy: theory and application. Ecosystems 17(4):578-589. http://dx.doi.org/10.1007/s10021-013-9744-2

Allen, C. R., H. E. Birge, S. Bartelt-Hunt, R. A. Bevans, J. L. Burnett, B. A. Cosens, X. Cai, A. S. Garmestani, I. Linkov, E. A. Scott, and M. D. Solomon. 2016. Avoiding decline: fostering resilience and sustainability in midsize cities. Sustainability 8 (9):844. http://dx.doi.org/10.3390/su8090844

Anderies, J. M., and J. Norberg. 2008. Theoretical challenges: information processing and navigation in social-ecological systems. Pages 155-179 in J. Norberg and G. S. Cumming, editors. Complexity theory for a sustainable future. Columbia University Press, New York, New York, USA.

Archer, M. S. 2003. Structure, agency, and the internal conversation. Cambridge University Press, Cambridge, UK.

Bandura, A. 1991. Social cognitive theory of self-regulation. Organizational Behavior and Human Decision Processes 50 (2):248-287. http://dx.doi.org/10.1016/0749-5978(91)90022-L

Barnes, W., M. Gartland, and M. Stack. 2004. Old habits die hard: path dependency and behavioral lock-in. Journal of Economic Issues 38(2):371-377. http://dx.doi.org/10.1080/00213624.2004.11506696

Battilana, J., B. Leca, and E. Boxenbaum. 2009. How actors change institutions: towards a theory of institutional entrepreneurship. Academy of Management Annals 3(1):65-107. http://dx.doi.org/10.5465/19416520903053598
Becker, E. 2012. Social-ecological systems as epistemic objects. Pages 37-59 in M. Glaser, G. Krause, B. M. W. Ratter, and M. Welp, editors. Human-nature interactions in the Anthropocene: potentials of social-ecological systems analysis. Routledge, New York, New York, USA.

Bennett, E. M., G. S. Cumming, and G. D. Peterson. 2005. A systems model approach to determining resilience surrogates for case studies. Ecosystems 8(8):945-957. http://dx.doi.org/10.1007/ s10021-005-0141-3

Berkes, F., and C. Folke. 1998. Linking social and ecological systems for resilience and sustainability. Pages 1-25 in F. Berkes, C. Folke, and J. Colding, editors. Linking sociological and ecological systems: management practices and social mechanisms for building resilience. Cambridge University Press, Cambridge, UK.

Brown, K. 2016. Resilience, development and global change. Routledge, New York, New York, USA.

Byrne, D., and G. Callaghan. 2014. Complexity theory and the social sciences: the state of the art. Routledge, London, UK.

Cash, D. W., W. Adger, F. Berkes, P. Garden, L. Lebel, P. Olsson, L. Pritchard, and O. Young. 2006. Scale and cross-scale dynamics: governance and information in a multilevel world. Ecology and Society 11(2):8. http://dx.doi.org/10.5751/ES-01759-110208

Chapin, F. S., III, C. Folke, and G. P. Kofinas. 2009. A framework for understanding change. Pages 3-28 in F. S. Chapin, III, G. P. Kofinas, and C. Folke, editors. Principles of ecosystem stewardship: resilience-based natural resource management in a changing world. Springer, New York, New York, USA. http://dx. doi.org/10.1007/978-0-387-73033-2_1

Chemero, A. 2009. Radical embodied cognitive science. MIT press, Cambridge, Massachusetts, USA.

Cochrane, W. W. 1993. The development of American agriculture: a historical analysis. University of Minnesota Press, Minneapolis, Minnesota, USA.

Cumming, G. S., G. Barnes, S. Perz, M. Schmink, K. E. Sieving, J. Southworth, M. Binford, R. D. Holt, C. Stickler, and T. Van Holt. 2005. An exploratory framework for the empirical measurement of resilience. Ecosystems 8:975-987. http://dx.doi. org/10.1007/s10021-005-0129-Z

Cumming, G. S., and J. Collier. 2005. Change and identity in complex systems. Ecology and Society 10(1):29. http://dx.doi. org/10.5751/ES-01252-100129

Cumming, G. S., P. Olsson, F. S. Chapin, III, and C. S. Holling. 2012. Resilience, experimentation, and scale mismatches in socialecological landscapes. Landscape Ecology 28(6):1139-1150. http://dx.doi.org/10.1007/s10980-012-9725-4

Cumming, G., and G. Peterson. 2005. Ecology in global scenarios. Pages 45-70 in S. R. Carpenter, P. L. Pingali, E. M. Bennett, and M. B. Zurek, editors. Ecosystems and human well-being: scenarios. Volume 2. Findings of the Scenarios Working Group, Millennium Ecosystem Assessment. Island Press, Washington, D.C., USA.

Ecotrust. 2005a. The new mainstream: a sustainable food agenda for California for review by the Roots of Change Council and the Roots of Change Fund. Ecotrust, Portland, Oregon, USA. 
Ecotrust. 2005b. Salmon Nation voices: adding value. Ecotrust, Portland, Oregon, USA.

Enfors, E. 2013. Social-ecological traps and transformations in dryland agro-ecosystems: using water system innovations to change the trajectory of development. Global Environmental Change 23(1):51-60. http://dx.doi.org/10.1016/j.gloenvcha.2012.10.007

Fazey, I. 2010. Resilience and higher order thinking. Ecology and Society 15(3):9. http://dx.doi.org/10.5751/ES-03434-150309

Felin, T., S. Kauffman, R. Koppl, and G. Longo. 2014. Economic opportunity and evolution: beyond landscapes and bounded rationality. Strategic Entrepreneurship Journal 8(4):269-282. http://dx.doi.org/10.1002/sej.1184

Folke, C. 2006. Resilience: the emergence of a perspective for social-ecological systems analyses. Global Environmental Change 16:253-267. http://dx.doi.org/10.1016/j.gloenvcha.2006.04.002

Folke, C. 2016. Resilience. Oxford research encyclopedia of environmental science. Oxford University Press, New York, New York, USA. http://dx.doi.org/10.1093/acrefore/9780199389414.013.8

Folke, C., S. R. Carpenter, B. Walker, M. Scheffer, T. Chapin, and J. Rockström. 2010. Resilience thinking: integrating resilience, adaptability and transformability. Ecology and Society 15(4):20. http://dx.doi.org/10.5751/ES-03610-150420

Folke, C., L. Pritchard, Jr., F. Berkes, J. Colding, and U. Svedin. 2007. The problem of fit between ecosystems and institutions: ten years later. Ecology and Society 12(1):30. http://dx.doi. org/10.5751/ES-02064-120130

Friedland, R., and R. R. Alford. 1991. Bringing society back in: symbols, practices, and institutional contradictions. Pages 232-266 in W. W. Powell and P. J. DiMaggio, editors. The new institutionalism in organizational analysis. University of Chicago Press, Chicago, Illinois, USA.

Fullerton, J. 2015. Regenerative capitalism: how universal principles and pattern will shape our new economy. Capital Institute. [online] URL: http://capitalinstitute.org/wp-content/ uploads/2015/04/2015-Regenerative-Capitalism-4-20-15-final.pdf

Gardner, B. L. 2002. American agriculture in the twentieth century: how it flourished and what it cost. Harvard University Press, Cambridge, Massachusetts, USA.

Gibson, C., E. Ostrom, and T. K. Ahn. 2000. The concept of scale and the human dimensions of global change: a survey. Ecological Economics 32:217-239. http://dx.doi.org/10.1016/S0921-8009(99) $\underline{00092-0}$

Gibson, J. J. 1979. The ecological approach to visual perception. Houghton Mifflin Company, Boston, Massachusetts, USA.

Hatt, K. 2013. Social attractors: a proposal to enhance "resilience thinking" about the social. Society \& Natural Resources: An International Journal 26(1):30-43. http://dx.doi.org/10.1080/089$\underline{41920.2012 .695859}$

Holling, C. S. 1973. Resilience and stability of ecological systems. Annual Review of Ecology and Systematics 4:1-24. http://dx.doi. org/10.1146/annurev.es.04.110173.000245
Holling, C. S. 2001. Understanding the complexity of economic, ecological, and social systems. Ecosystems 4:390-405. http://dx. doi.org/10.1007/s10021-001-0101-5

Ison, R. 2010. Systems practice: how to act in a climate change world. Springer, London, UK. http://dx.doi.org/10.1007/978-1-84996-125-7

Kauffman, S. A. 2000. Investigations. Oxford University Press, Oxford, UK.

Kauffman, S. A., and A. Gare. 2015. Beyond Descartes and Newton: recovering life and humanity. Progress in Biophysics and Molecular Biology 119(3):219-244. http://dx.doi.org/10.1016/j. pbiomolbio.2015.06.003

Kim, D. H., and V. Anderson. 1998. System archetype basics: from story to structure. Pegasus Communications, Waltham, Massachusetts, USA.

Lev, L., and G. W. Stevenson. 2013. Values-based food supply chains: Shepherd's Grain. The National Initiative on Agriculture of the Middle and The Center for Integrated Agricultural Systems, University of Wisconsin-Madison. [online] URL: $\underline{\text { http:// }}$ agofthemiddle.org/wp-content/uploads/2015/05/

shepherdsgrainfinal071613.pdf

Mahoney, J. 2000. Path dependence in historical sociology. Theory and Society 29(4):507-548. http://dx.doi.org/10.1023/A:1007113830879

Manuel-Navarrete, D. 2015. Double coupling: modeling subjectivity and asymmetric organization in social-ecological systems. Ecology and Society 20(3):26. http://dx.doi.org/10.5751/ ES-07720-200326

Masten, A. S., and J. Obradović. 2008. Disaster preparation and recovery: lessons from research on resilience in human development. Ecology and Society 13(1):9. http://dx.doi. org/10.5751/ES-02282-130109

Moore, M.-L., O. Tjornbo, E. Enfors, C. Knapp, J. Hodbod, J. A. Baggio, A. Norström, P. Olsson, and D. Biggs. 2014. Studying the complexity of change: toward an analytical framework for understanding deliberate social-ecological transformations. Ecology and Society 19(4):54. http://dx.doi.org/10.5751/ ES-06966-190454

Moore, M.-L., and F. Westley. 2011. Surmountable chasms: networks and social innovation for resilient systems. Ecology and Society 16(1):5. http://dx.doi.org/10.5751/ES-03812-160105

Olsson, P., V. Galaz, and W. J. Boonstra. 2014. Sustainability transformations: a resilience perspective. Ecology and Society 19 (4):1. http://dx.doi.org/10.5751/ES-06799-190401

Olsson, P., M.-L. Moore, F. R. Westley, and D. D. P. McCarthy. 2017. The concept of the Anthropocene as a game-changer: a new context for social innovation and transformations to sustainability. Ecology and Society 22(2):31. http://dx.doi. org/10.5751/ES-09310-220231

Pache, A. C., and F. Santos. 2013. Inside the hybrid organization: selective coupling as a response to competing institutional logics. Academy of Management Journal 56(4):972-1001. http://dx.doi. org/10.5465/amj.2011.0405 
Page, S. E. 2006. Path dependence. Quarterly Journal of Political Science 1:87-115.

Patton, M. Q. 2015. Qualitative research \& evaluation methods: integrating theory and practice. Fourth edition. SAGE Publications, Thousand Oaks, California, USA.

Pelling, P., M. Manuel-Navarrete, and R. Redclift, editors. 2012. Climate change and the crisis of capitalism: a chance to reclaim, self, society and nature. Routledge, London, UK.

Pierson, P. 2015. Power and path dependence. Pages 123-146 in J. Mahoney and $\mathrm{K}$. Thelen, editors. Advances in comparativehistorical analysis. Cambridge University Press, Cambridge, UK. http://dx.doi.org/10.1017/CBO9781316273104.006

Rapoport, A. 1985. Thinking about home environments: a conceptual framework. Pages 255-286 in I. Altman and C. M. Werner, editors. Home environments. Plenum Press, New York, New York, USA. http://dx.doi.org/10.1007/978-1-4899-2266-3 11

Raymond, C. M., M. Giusti, and S. Barthel. 2017. An embodied perspective on the co-production of cultural ecosystem services: toward embodied ecosystems. Journal of Environmental Planning and Management 61(5-6):778-799. http://dx.doi.org/10.1080/096$\underline{40568.2017 .1312300}$

Resilience Alliance. 2010. Assessing resilience in social-ecological systems: workbook for practitioners. Version 2.0.

Rockström, J. 2014. Plenary session 2: which development pathways within planetary boundaries? Resilience 2014, Montpellier, France, May 7, 2014. [online] URL: http://www. resilience2014.org/outputs-outcomes/videos\#session2

Sayer, A. 1992. Method in social science: a realist approach. Second edition. Routledge, London, UK.

Scheffer, M. 2009. Critical transitions in nature and society. Princeton University Press, Princeton, New Jersey, USA.

Sendzimir, J., P. Magnuszewski, Z. Flachner, P. Balogh, G. Molnar, A. Sarvari, and Z. Nagy. 2007. Assessing the resilience of a river management regime: informal learning in a shadow network in the Tisza River Basin. Ecology and Society 13(1):11. http://dx.doi.org/10.5751/ES-02239-130111

Senge, P. M. 1990. The fifth discipline: the art \& practice of the learning organization. Currency/Doubleday, New York, New York, USA.

Silverman, H., E. Brady, and K. Meter. 2005. Sustainable food systems: working towards a fundamental solution. Ecotrust, Portland, Oregon, USA.

Smith, A., and A. Stirling. 2010. The politics of social-ecological resilience and sustainable socio-technical transitions. Ecology and Society 15(1):11. http://dx.doi.org/10.5751/ES-03218-150111

Stryker, S., and P. J. Burke. 2000. The past, present, and future of an identity theory. Social Psychology Quarterly 63(4):284-297. http://dx.doi.org/10.2307/2695840

Swim, J., S. Clayton, T. Doherty, R. Gifford, G. Howard, J. Reser, P. Stern, and E. Weber. 2009. Psychology and global climate change: addressing a multi-faceted phenomenon and set of challenges. A report by the American Psychological Association's task force on the interface between psychology and global climate change. American Psychological Association, Washington D.C., USA.

Thornton, P. H., W. Ocasio, and M. Lounsbury. 2012. The institutional logics perspective: a new approach to culture, structure, and process. Oxford University Press, Oxford, UK. http://dx.doi. org/10.1093/acprof:oso/9780199601936.001.0001

van Lieshout, M., A. Dewulf, N. Aarts, and C. Termeer. 2011. Do scale frames matter? Scale frame mismatches in the decision making process about a "mega farm" in a small Dutch village. Ecology and Society 16(1):38. http://dx.doi.org/10.5751/ ES-04012-160138

Vervoort, J. M., L. Rutting, K. Kok, F. L. P. Hermans, T. Veldkamp, A. K. Bregt, and R. van Lammeren. 2012. Exploring dimensions, scales, and cross-scale dynamics from the perspectives of change agents in social-ecological systems. Ecology and Society 17(4):24. http://dx.doi.org/10.5751/ ES-05098-170424

Vickers, G. 1980. Responsibility - its sources and limits. Intersystems Publications, Seaside, California, USA.

Walker, B. H., S. R. Carpenter, J. Rockstrom, A.-S. Crépin, and G. D. Peterson. 2012. Drivers, "slow" variables, "fast" variables, shocks, and resilience. Ecology and Society 17(3):30. http://dx.doi. org/10.5751/ES-05063-170330

Walker, B. H., L. H. Gunderson, A. P. Kinzig, C. Folke, S. R. Carpenter, and L. Schultz. 2006. A handful of heuristics and some propositions for understanding resilience in social-ecological systems. Ecology and Society 11(1):13. http://dx.doi.org/10.5751/ ES-01530-110113

Walker, B., C. S. Holling, S. R. Carpenter, and A. Kinzig. 2004 Resilience, adaptability and transformability in social-ecological systems. Ecology and Society 9(2):5. http://dx.doi.org/10.5751/ ES-00650-090205

Walker, B., and D. Salt. 2006. Resilience thinking: sustaining ecosystems and people in a changing world. Island Press, Washington, D.C., USA.

Walker, B., and D. Salt. 2012. Resilience practice: building capacity to absorb disturbance and maintain function. Island Press, Washington, D.C., USA.

Westley, F. 2002. The devil in the dynamics: adaptive management on the front lines. Pages 333-360 in L. H. Gunderson and C. S. Holling, editors. Panarchy: understanding transformation in human and natural systems. Island Press, Washington, D.C., USA.

Westley, F., S. R. Carpenter, W. A. Brock, C. S. Holling, and L. Gunderson. 2002. Why systems of people and nature are not just social and ecological systems. Pages 103-119 in L. H. Gunderson and C. S. Holling, editors. Panarchy: understanding transformation in human and natural systems. Island Press, Washington, D.C., USA.

Westley, F. R., K. A. McGowan, N. Antadze, J. Blacklock, and O. Tjornbo. 2016. How game changers catalyzed, disrupted, and incentivized social innovation: three historical cases of nature conservation, assimilation, and women's rights. Ecology and Society 21(4):13. http://dx.doi.org/10.5751/ES-08811-210413 
Westley, F., P. Olsson, C. Folke, T. Homer-Dixon, H. Vredenburg, D. Loorbach, J. Thompson, M. Nilsson, E. Lambin, J. Sendzimir, B. Banerjee, V. Galaz, and S. van der Leeuw. 2011. Tipping toward sustainability: emerging pathways of transformation. Ambio 40 (7):762-780. http://dx.doi.org/10.1007/s13280-011-0186-9

White, H. C. 2008. Identity and control: how social formations emerge. Second edition. Princeton University Press, Princeton, New Jersey, USA. http://dx.doi.org/10.1515/9781400845903 